\title{
ANALISA KINERJA SUATU PERUSAHAAN DI JAKARTA DENGAN MENGGUNAKAN BALANCED SCORECARD
}

\section{[A Company Performance Analysis in Jakarta Using Balanced Scorecard]}

\author{
Antonius Felix ${ }^{1)}$ \\ ${ }^{1)}$ Program Studi Bisnis Digital, Universitas Bunda Mulia \\ Diterima 09-09-2020 / Disetujui 31-05-2021
}

\begin{abstract}
The research was conducted at a distribution company in Jakarta by measuring performance using the Balanced Scorecard in order to analyze the overall perspective, including financial, customer, business process, and learning and growth perspectives. The research method is by field survey, interview and questionnaire. The problem is the decline in company sales since 2017. The data collection technique that the writer does is by field research, direct research on the object. The data used are primary data and secondary data. The results showed that the company is in good health, the lowest perspective is the perspective of internal business processes, although other perspectives are in good condition, there is still a need for continuous progress. Companies need to add product lines, at least add new suppliers, because in this perspective it is very low and makes the bargaining power of suppliers high. In fact, if possible start to start your own brand. Reassigning job descriptions because some systems are no longer suitable for new employees, have to be adjusted again and need to fill empty seats so as not to be too burdensome for certain individuals. The suggestion of this research is that there are several things that must be considered, suggesting additional suppliers, slow after sales sales, better SOP and reward system.
\end{abstract}

Keywords: Balanced Scorecard, performance analysis, strategic management

\begin{abstract}
ABSTRAK
Penelitian dilakukan di sebuah perusahaan distribusi di Jakarta dengan melakukan pengukuran kinerja menggunakan Balanced Scorecard agar bisa menganalisa secara keseluruhan perspektif antara lain perspektif keuangan, pelanggan, proses bisnis, dan pembelajaran dan pertumbuhan. Metode penelitian adalah dengan survey lapangan, wawancara dan kuesioner. Permasalahan adalah penurunan penjualan perusahaan sejak tahun 2017. Teknik Pengumpulan data yang penulis lakukan adalah dengan penelitian lapangan, penelitian langsung pada objek yang diteliti. Data yang digunakan adalah data primer dan data sekunder. Hasil penelitian menunjukan bahwa perusahaan dalam keadaan sehat, perspektif yang paling rendah adalah perspektif proses bisnis internal, walau perspektif lain dalam keadaan baik, namum tetap perlu adanya kemajuan berkelanjutan. Perusahaan perlu untuk menambahkan lini product, setidaknya menambah supplier baru, karena di perspektif ini sangat rendah dan membuat bargaining power dari supplier tinggi. Malah jika memungkinkan mulai untuk memulai brand sendiri. Melakukan penugasan kembali job description karena beberapa sistem sudah tidak sesuai dengan karyawan yang baru, harus di sesuaikan lagi dan perlu mengisi kursi- kursi yang memang kosong supaya tidak terlalu pembebanan di individu - individu tertentu. Saran dari penelitian ini ada beberapa hal yang harus diperhatikan disarankan penambahan supplier, aftersales lambat, harus adanya SOP yang lebih baik dan sistem reward.
\end{abstract}

Kata Kunci: Balanced Scorecard, pengukuran kinerja, manajemen strategis

\section{PENDAHULUAN}

Di masa saat ini semua bisnis dihadapkan dengan perkembangan yang sangat cepat baik dari sisi bisnis itu sendiri maupun kegiatan - kegiatan pendukungnya, terutama perkembangan teknologi informasi. Perusahaan harus beradapasi secara cepat secara struktur organisasi serta sistem - sistem di dalamnya. Perusahaan harus mampu

\footnotetext{
*Korespondensi Penulis:

E-mail: Antoniusfelix90@gmail.com
} 
berkiblat ke kepuasan pelanggan (customer oriented), karena pelanggan di era serba digital saat ini lebih well informed.

Dikutip dari situs resmi bank dunia, pada tanggal 9 September 2019, Direktur utama Global Bank Dunia yang di kutip oleh kompas.com mengatakan "Di awal tahun 2018 pertumbuhan ekonomi global melaju dengan pesat, namun mulai kehilangan lajunya seiring dengan berjalannya waktu, dan perjalanan akan semakin bergejolak setahun ke depan,". Sementara di dalam negeri, pertumbuhan ekonomipun tidak semanis yang diharapkan, dikutip dari artikel liputan 6, Sri Mulyani selaku Menteri ekonomi menjelaskan bahwa baik kinerja konsumsi masyarakat pada quarter pertama hanya 5,08\%, jauh di bawah target APBN sebesar 5,3\%. Dari pola tren dunia dan dalam negeri hasilnya menunjukan hasil yang mirip bahwa masyarakat sudah mulai mengerem konsumsi.

Di lain sisi pertumbuhan UMKM di Indonesia berkembang dengan pesat, data dari Kementerian Koperasi dan Usaha Kecil dan Menengah Republik Indonesia selama 5 tahun 2012-2017 sebesar $13,98 \%$ atau rata-rata $2,8 \%$ pertahun sedangkan untuk perusahaan besar sebesar $10,26 \%$ atau $2.04 \%$ pertahun. Jika kita bandingkan data perkembangan usaha dan daya beli masyarakat yang turun, menjadi tantangan bagi industri untuk semakin kreatif untuk mendapatkan pangsa pasarnya atau akan hilang dari persaingan.

Permasalahan utama yang penulis soroti adalah penurunan penjualan PT. AGP yang pada tahun dari tahun 2017, berikut adalah data penjualan PT. AGP pada tahun 2018 dan 2019 dapat dilihat di Tabel 1.

Tabel 1 Laporan Penjualan PT AGP (dalam rupiah)

\begin{tabular}{lllccc}
\hline $\mathbf{2 0 1 7}$ & $\begin{array}{l}\text { Rata }- \\
\text { rata } \\
\text { perbul } \\
\text { an }\end{array}$ & $\mathbf{2 0 1 8}$ & $\begin{array}{c}\text { Rata }- \\
\text { rata } \\
\text { perbul } \\
\text { an }\end{array}$ & $\begin{array}{c}\mathbf{2 0 1 9} \\
\text { s/d } \\
\text { 31Juli }\end{array}$ & $\begin{array}{c}\text { Rata - } \\
\text { rata } \\
\text { perbul } \\
\text { an }\end{array}$ \\
\hline $8,810,6$ & 734,21 & $6,660,9$ & 555,07 & $2,981,8$ & 425,97 \\
04,843 & 7,070 & 49,124 & 9,094 & 23,500 & 4,786
\end{tabular}

Sumber : Data Perusahaan
Rata-rata di tahun 2017 sebesar 734.217.070 perbulan (data dari 1 Januari 2017 sampai dengan 31 Desember 2017) menjadi 555.079.094 perbulan (data dari 1 Januari 2018 - 31 Desember 2018), dan yang data terkini dari tanggal 1 Januari 2019 sampai dengan 31 Juli 2019 adalah rata-rata 425.974.786 perbulan. Dalam penulisan ini diharapkan dapat memberikan gambaran dan indikator hingga dapat mengetahui apa penyebab dari penurunan penjualan PT AGP.

Gambaran posisi perusahaan dari dua sumber yaitu gambaran finansial dan gambaran non finansial. Gambaran finansial digunakan untuk melakukan penyusunan anggaran guna pengendalian biaya. Gambaran non finansial digunakan untuk melihat tingkat kesehatan perusahaan dan dapat digunakan untuk penentuan rewarding bagi para pekerja. Pihak manajemen juga dapat menggunakan pengukuran kinerja perusahaan sebagai alat untuk mengevaluasi periode yang lalu. (Hardiyanto, et al, 2005).

Sampai saat ini pengukuran kinerja perusahaan hanya sebatas kinerja keuangan, tapi dengan seiring perkembangannya saat ini dan kemerosotan penjualan, penulis merasa harus menelaah aspek - aspek yang lebih luas. Mengutip dari penelitian yang di lakukan oleh Erwin \& Prabowo, 2015 memiliki permasalahan serupa dengan yang di alami oleh PT AGP, Menurut Luis \& Biromo, 2010 Balanced Scorecard memiliki kelebihankelebihan sebagai berikut: (1) Balanced Scorecard (BSC) dapat berfungsi sebagai alat ukur untuk mengkomunikasikan strategi di antara para stakeholders dari sebuah organisasi. (2) Balanced Scorecard memungkinkan organisasi untuk memetakan semua faktor utama yang ada dalam organisasi tersebut, baik yang berbentuk benda fisik (tangible) maupun benda non fisik (intangible). (3) Balanced Scorecard dapat mengaitkan strategi dengan kinerja organisasi (performance). Proses pelaksanaan itu dapat dipantau tingkat pencapaiannya dengan menggunakan Key Performance Indicators yang biasa disingkat menjadi KPI. Hal ini 
menunjukkan bahwa $B S C$ tidak hanya membantu organisasi dalam menyusun strategi, tetapi juga memonitor pencapaian strategi tersebut. (4) Balanced Scorecard memiliki konsep sebab-akibat. Dengan demikian para pelaku strategi mendapat gambaran dan menjadi jelas bahwa bila strategi yang berada dalam tanggung jawab mereka dapat tercapai dengan sukses, hal itu akan membuahkan hasil tertentu dan akan terkait dengan strategi lainnya. Sebaliknya bila tak tercapai, hal itu pada gilirannya akan mempengaruhi pencapaian strategi lainnya. (5) Balanced Scorecard dapat membantu proses penyusunan anggaran. Dari BSC dapat diketahui kegiatan apa saja yang harus dilakukan organisasi guna mencapai targettargetnya yang meliputi aktivitas sehari-hari sampai dengan proyek-proyek khusus. Hubungan dengan penelitian ini adalah samasama mengeksplorasi konsep Balanced Scorecard untuk mengukur kinerja perusahaan.

Berdasarkan permasalahan pada PT AGP, penulis memilih metode Balanced Scorecard karena dirasa penting untuk melakukan analisis menyeluruh tidak hanya sebatas indikator keuangan yang tidak lagi relevan dengan persaingan bisnis yang semakin cerdas saat ini.

\section{METODE PENELITIAN}

\section{Desain Penelitian, Teknik Pengumpulan} Data dan Teknik Pengambilan Sampel

\begin{tabular}{clll}
\multicolumn{3}{c}{ Tabel 2 Desain Penelitian } \\
\hline $\begin{array}{c}\text { Tujuan } \\
\text { Penelitian }\end{array}$ & \multicolumn{3}{c}{ Desain Penelitian } \\
\cline { 2 - 4 } & $\begin{array}{l}\text { Jenis dan } \\
\text { Metode }\end{array}$ & Unit Analisis & $\begin{array}{l}\text { Horizon } \\
\text { Waktu }\end{array}$ \\
\hline $\begin{array}{c}\text { Mengukur } \\
\text { kinerja }\end{array}$ & $\begin{array}{l}\text { Deskriptif } \\
\text { analisis / } \\
\text { studi kasus, } \\
\text { interview }\end{array}$ & Perusahaan & $\begin{array}{l}\text { Cross- } \\
\text { Sectional }\end{array}$ \\
\hline $\begin{array}{c}\text { Menganalisis } \\
\text { hasil ukuran } \\
\text { kerja }\end{array}$ & $\begin{array}{c}\text { Deskriptif } \\
\text { analisis / } \\
\text { studi kasus }\end{array}$ & Perusahaan & Cross- \\
Mengetahui \\
langkah- \\
langkah & $\begin{array}{c}\text { Deskriptif } \\
\text { analisis / } \\
\text { kedepannya }\end{array}$ & Perusahaan & Sectional \\
\hline
\end{tabular}

Sumber : Dokumen Pribadi
Tabel 2 adalah desain penelitian pada penulisan ini. Desain penelitian yang di gunakan adalah dengan deskriptif analisis / studi kasus, Metode penelitian deskriptif ini dilakukan untuk mengetahui keberadaan variabel mandiri, baik hanya pada sat variabel atau lebih (variabel yang berdiri sendiri atau variabel bebas) tanpa membuat perbandingan variabel itu sendiri dan mencari hubungan dengan variabel lain (Sugiyono, 2017)

Unit analisis adalah perusahaan yang berarti data yang dikumpulkan adalah dari data internal perusahaan berikut sumber daya manusia nya seperti bagian penjualan dan bagian pembukuan dan keuangan. Time Horizon dengan cross - sectional yang berarti disini penulis mengambil data dari perusahaan dengan periode waktu sekali pengambilan, data yang belum diolah di berikan kepada penulis seperti laporan - laporan keuangan, dan penulis olah dalam penelitian ini.

Pengelompokan data dalam penelitian ini diawali dengan mendisain pertanyaan untuk interview, lalu di analisis apakah cocok, jika tidak cocok akan diperbaiki dan baru ke tahap selanjutnya lagi. Jika pertanyaan sudah dianggap valid lalu ke tahap selanjutnya yaitu pengambilan data-data, selanjutnya memproses data yang telah di dapat dan akhirnya bisa menarik kesimpulan. (Andry, 2018) dapat dilihat pada gambar 1

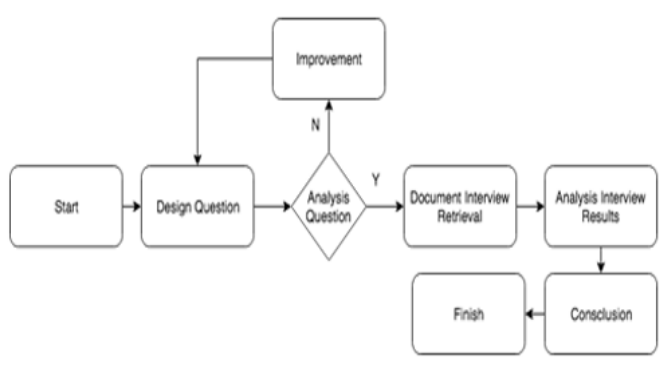

Gambar 1 Tahapan Penelitian Sumber : Andry (2018).

Teknik Pengumpulan data yang penulis lakukan adalah dengan penelitian lapangan, penelitian langsung pada objek yang di teliti guna mendapatkan gambaran yang menyeluruh. Data yang diambil melalui, interview dan observasi. Peneliti juga menggunakan penelitian kepustakaan, 
bertujuan untuk mendapatkan data-data sekunder.

Proses pengolahan data interview mengadopsi dari proses interview Andry (2018) pada jurnalnya, Interview akan dilakukan kepada perusahaan, yang menjadi narasumber di penelitian ini adalah CEO dari PT AGP. Pertanyaan akan dianalisis, jika pertanyaan tersebut telah sesuai dengan keadaan perusahaan maka dapat dilanjutkan ke tahap wawancara, jika tidak maka penulis melakukan perbaikan pada bagian pertanyaan yang kurang sejalan dengan perusahaan. Wawancara dilakukan dengan pihak-pihak yang memahami topik terkait. Setelah wawancara, peneliti akan mencari data sebagai verifikasi / bukti hasil wawancara. Setelah memverifikasi, memberikan laporan hasil audit dan rekomendasi untuk perusahaan. Tahap wawancara dapat dilihat pada Gambar 2.

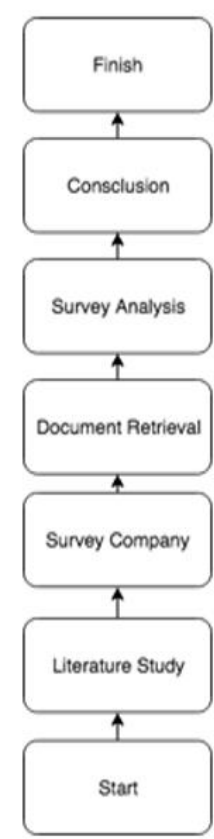

Gambar 2 Interview Process Diagram Sumber : Andry (2018).

\section{Variabel dan Pengkuruannya}

Pengukuran kepada aktivitas yang telah dilakukan oleh perusahaan, yang diukur secara kualitatif maupun kuantitatif (Kaplan, 1996).

1. Perspektif Keuangan
Pada saat perusahaan melakukan pengukuran finansial, maka hal yang utama adalah mengetahui posisi perusahaan dalam industri (Kaplan, 1996). Pengukuran pada perspektif ini antara lain likuiditas yang adalah kemampuan perusahaan dalam memenuhi kewajiban jangka pendeknya. Yang kedua adalah solvabilitas untuk mengukur kemampuan perusahaan dalam memenuhi kewajiban jangka panjangnya. Ketiga rentabilitas yang mengukur tingkat efisiensi manajemen. Dan yang keempat adalah rasio aktvitas yang mengukur kecepatan beberapa perkiraan agar menjadi penjualan atau cash

2. Perspektif Pelanggan

Perspektif ini pengukuran pelanggan mengacu pada lima aspek utama yaitu customer retention, customer acquisition, customer satisfaction dan customer profitability (Kaplan, 1996).

3. Perspektif Proses Bisnis Internal Pengukuran dalam perspektif ini adalah yang bersangkutan dengan aktvitas yang dilakukan oleh perusahaan di semua tingkatan untuk menghasilkan suatu produk yang dapat memenuhi kepuasan tertentu bagi customer dan pemegang saham. Tiga proses antaranya adalah proses inovasi, proses operasi dan proses pasca proses pendidikan.

4. Perspektif Pembelajaran dan Pertumbuhan

Perspektif ini berkaitan dengan sumber daya manusia, sistem dan prosedur organisaasi. Contohnya adalah training karyawan, budaya perusahaan yang berhubungan dengan perkembangan individu dan perusahaan. Perusahaan diharapkan menjadi sebuah organisasi pembelajar. 


\section{HASIL DAN PEMBAHASAN}

PT AGP adalah sebuah perusahaan distribusi dengan beberapa kategori unggulan seperti aksesoris computer dan ponsel, system kamera keamanan, kamera pesawat tanpa awak (drone). Area penjualan utamanya adalah Jakarta, Tangerang, Bekasi, dan sebagian Depok. Sebagai authorized distributor dari beberapa brand, PT AGP menjual secara $\mathrm{B} 2 \mathrm{~B}$ pada toko, proyek pengadaan souvenir, toko konvensional di mall dan online.

Visi dari PT AGP adalah menjadi perusahaan yang dapat maju bersama-sama memperoleh keuntungan maksimum dengan para pelanggannya dan mensejahterakan para karyawannya. Maksudnya dari visinya adalah, dimana toko yang menjadi customer AGP mendapatkan keuntungan yang maksimal dan dapat maju ke depannya dan tambah besar. Serta untuk segi karyawan, PT AGP mau karyawannya sejahtera terutama urusan taraf hidup, dimana dalam kategori cukup dan adanya peningkatan kualitas kesejahteraan, disini menjelaskan bahwa PT AGP juga memiliki care pada para karyawannya.

Balanced Scorecard yang dalam penelitian ini tidak lepas dari visi misi perusahan yang disebut tujuan strategis. Dimana 4 perspektif akan bertujuan mendukung akhir tercapainya tujuan strategis tersebut. Hubungan antara 4 perspektif dan tujuan strategis perusahaan di gambarkan pada gambar 3 .

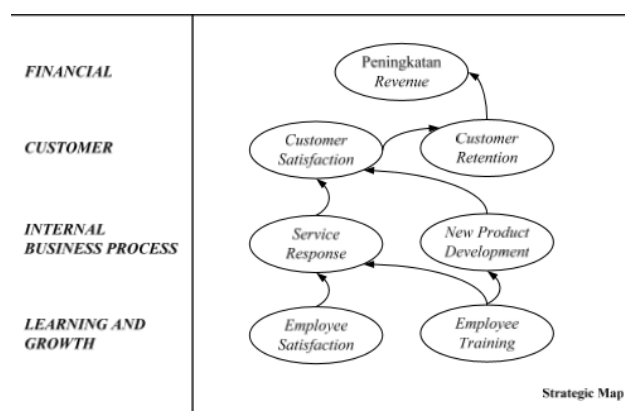

Gambar 3 BSC Strategic Map (Widyaningrum \& Kabul, 2014)
Untuk dapat mencapai Tujuan Strategis, tentunya perlu ada ukuran tertentu, karena kita tidak bisa mencapai apa yang tidak terukur (Kaplan, 1996). Maka dirumuskan pada tabel 3.

\section{Tabel 3 BSC Ukuran Strategis Perusahaan}

\begin{tabular}{|c|c|c|}
\hline Perspektif & Tujuan Strategis & Ukuran Strategis \\
\hline \multirow{2}{*}{$\begin{array}{l}\text { Perspektif } \\
\text { Keuangan }\end{array}$} & \multirow{2}{*}{$\begin{array}{l}\text { Peningkatan } \\
\text { Revenue }\end{array}$} & Total penjualan \\
\hline & & Rasio Lancar \\
\hline \multirow{7}{*}{$\begin{array}{l}\text { Perspektif } \\
\text { Pelanggan }\end{array}$} & \multirow{6}{*}{$\begin{array}{l}\text { Customer } \\
\text { Satisfaction }\end{array}$} & $\begin{array}{l}\text { Mutu dan Kualitas } \\
\text { Produk }\end{array}$ \\
\hline & & $\begin{array}{l}\text { Kualitas layanan dan } \\
\text { fasilitas yang tersedia }\end{array}$ \\
\hline & & $\begin{array}{l}\text { Kemudahan term } \\
\text { pembayaran }\end{array}$ \\
\hline & & $\begin{array}{l}\text { Persepsi customer } \\
\text { tentang kecepatan } \\
\text { pengiriman perusahaan }\end{array}$ \\
\hline & & $\begin{array}{l}\text { Persentase barang rusak } \\
\text { (retur) }\end{array}$ \\
\hline & & $\begin{array}{l}\text { Hubungan komunikasi } \\
\text { pelanggan dan } \\
\text { perusahaan }\end{array}$ \\
\hline & $\begin{array}{l}\text { Customer } \\
\text { Retention }\end{array}$ & $\begin{array}{l}\text { Jumlah referal baru dari } \\
\text { existing customer }\end{array}$ \\
\hline \multirow{5}{*}{ Proses Bisnis } & \multirow{3}{*}{ Service Response } & $\begin{array}{l}\text { Persentase barang yang } \\
\text { tidak terkirim di hari } \\
\text { yang sama }\end{array}$ \\
\hline & & $\begin{array}{l}\text { Kecepatan } \\
\text { pengembalian barang } \\
\text { retur }\end{array}$ \\
\hline & & $\begin{array}{l}\text { Kecepatan Pengiriman } \\
\text { Pesananan ke Customer }\end{array}$ \\
\hline & \multirow{2}{*}{$\begin{array}{l}\text { New Products } \\
\text { Development }\end{array}$} & Proses inovasi product \\
\hline & & $\begin{array}{l}\text { proses inovasi proses } \\
\text { internal }\end{array}$ \\
\hline \multirow{7}{*}{$\begin{array}{l}\text { Learning \& } \\
\text { Growth }\end{array}$} & \multirow{6}{*}{$\begin{array}{l}\text { Employee } \\
\text { Satisfaction }\end{array}$} & Gaji dan tunjangan \\
\hline & & Fasilitas yang di dapat \\
\hline & & $\begin{array}{l}\text { Hubungan komunikasi } \\
\text { sesama karyawan }\end{array}$ \\
\hline & & $\begin{array}{l}\text { Hubungan antar level } \\
\text { management }\end{array}$ \\
\hline & & $\begin{array}{l}\text { Penghargaan terhadap } \\
\text { prestasi kerja }\end{array}$ \\
\hline & & $\begin{array}{l}\text { Pembagian tugas dalam } \\
\text { perusahaan }\end{array}$ \\
\hline & $\begin{array}{l}\text { Employee } \\
\text { Training }\end{array}$ & Training bagi karyawan \\
\hline
\end{tabular}

Ukuran strategis digunakan untuk menentukan dimana posisi perusahaan pada tujuan strategis perusahaan, maka kita perlu juga menentukan pembobotan yang cocok. Maka dibuat lah skala (Erwin \& Prabowo, 2015) seperti pada tabel 4. 
Tabel 4 Skala Pembobotan BSC

(Erwin \& Prabowo, 2015)

\begin{tabular}{llllll}
\hline Nilai & $1-1,9$ & $2-2,9$ & $3-3,9$ & $4-4,9$ & 5 \\
\hline Keteranga & Sangat & Buru & Cuku & Baik & Sangat \\
$\mathrm{n}$ & Buruk & $\mathrm{k}$ & $\mathrm{p}$ & & Baik \\
\hline
\end{tabular}

\section{Pengukuran Kinerja Perspektif Keuangan}

Tabel 5 BSC Perspekif Keuangan

\begin{tabular}{lccccc}
\hline \multicolumn{5}{c}{ Laporan Kinerja Menggunakan Metode Balanced Scorecard } \\
\hline \multicolumn{5}{c}{ Rata-rata perbulan dari 1 Januari 2018 - 31 Juli 2019 } \\
\hline $\begin{array}{l}\text { Ukuran } \\
\text { Strategis }\end{array}$ & Target/bln & satuan & Rata2/bln & Pencapaian & Bobot \\
\hline $\begin{array}{l}\text { Total } \\
\text { penjualan }\end{array}$ & $734,217,070$ & rupiah & $535,677,249$ & $73 \%$ & 3.65 \\
\hline $\begin{array}{l}\text { Rasio } \\
\text { Lancar }\end{array}$ & 2 & kali & 2.5 & $100 \%$ & 5.00 \\
\hline \multicolumn{5}{c}{ total rata - rata } \\
\hline
\end{tabular}

Sumber : Hasil Pengolahan Data

Tabel 5 adalah BSC dari persepektif keuangan. Data yang di dapat dari perusahaan adalah data penjualan 1Januari 2017 - 31 Juli 2019. Target dari perusahaan adalah rata- rata penjualan perbulan pada tahun 2017 sebesar 734,217,070. Namun selama tahun 2018 dan 2019 rata- rata perbulan tidak pernah achieve dan jika dirata-ratakan hanya 535,677,249 dengan kata lain hanya pencapaian di $73 \%$ dan mendapatkan skor pembobotan 3.65. Lalu untuk rasio lancer (current ratio) dari PT AGP sangat baik karena justru diatas target, berarti keuangan di perusahaan masih sangat liquid. Rata - rata dari perspektif keuangan adalah 4.32.

\section{Pengukuran Kinerja Perspektif Pelanggan}

Tabel 6 BSC Perspekif Pelanggan

\begin{tabular}{|c|c|c|c|c|c|}
\hline \multicolumn{6}{|c|}{ Rata-rata perbulan dari 1 Januari 2018 - 31 Juli 2019} \\
\hline Ukuran Strategis & $\begin{array}{l}\text { Target/b } \\
\text { In }\end{array}$ & satuan & $\begin{array}{l}\text { Rata2/b } \\
\text { In }\end{array}$ & $\begin{array}{l}\text { Pencapai } \\
\text { an }\end{array}$ & Bobot \\
\hline $\begin{array}{l}\text { Mutu dan Kualitas } \\
\text { Produk }\end{array}$ & 5 & skala & 3 & $60 \%$ & 3.00 \\
\hline $\begin{array}{l}\text { Kualitas layanan } \\
\text { dan fasilitas yang } \\
\text { tersedia }\end{array}$ & 5 & skala & 4 & $80 \%$ & 4.00 \\
\hline $\begin{array}{l}\text { Kemudahan term } \\
\text { pembayaran }\end{array}$ & 5 & skala & 5 & $100 \%$ & 5.00 \\
\hline $\begin{array}{l}\text { Persepsi customer } \\
\text { tentang kecepatan } \\
\text { pengiriman } \\
\text { perusahaan }\end{array}$ & 5 & skala & 3 & $60 \%$ & 3.00 \\
\hline
\end{tabular}

\begin{tabular}{lccccr}
\hline $\begin{array}{l}\text { Persentase barang } \\
\text { rusak (retur) }\end{array}$ & 5 & skala & 3 & $60 \%$ & 3.00 \\
\hline $\begin{array}{l}\text { Hubungan } \\
\text { komunikasi } \\
\text { pelanggan dan } \\
\text { perusahaan }\end{array}$ & & & & & \\
\hline $\begin{array}{l}\text { Jumlah referal } \\
\text { baru dari existing } \\
\text { customer }\end{array}$ & 5 & skala & 3 & $60 \%$ & 3.00 \\
\hline & 3 & $\begin{array}{l}\text { custom } \\
\text { er }\end{array}$ & 0.72 & $24 \%$ & 1.20 \\
\hline & total rata - rata BSC perspektif pelanggan & & 3.1 \\
\hline
\end{tabular}

Sumber : Hasil Pengolahan Data

Tabel 6 adalah BSC pada perspektif pelanggan. Data yang diambil dari 40 orang customer kami menunjukkan hasil yang tidak jauh berbeda antara satu orang dengan yang lainnya. Rata - rata perspektif pelanggan 3.17 yang masih berarti cukup baik. Namun sangat rendah pada pertumbuhan customer baru.

\section{Pengukuran Kinerja Perspektif Proses Bisnis Internal}

\section{Tabel 7 BSC Perspekif Proses Bisnis}

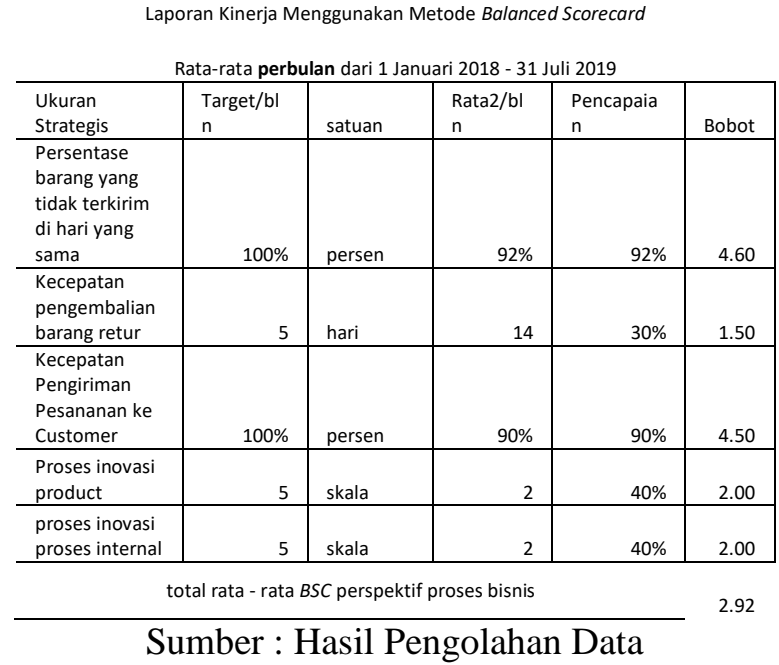

Interview yang kita lakukan untuk perspektif ini dengan melakukan interview kepada $C E O$, belum ada divisi khusus yang menangani bagian proses bisnis. Untuk penjualan dilihat sudah baik pengirimannya, namun untuk after sales dimana menukar barang rusak pelanggan dengan barang yang bagus masih sangat jauh dari yang target, yang idealnya 5 hari menurut hasil interview namun bisa di selesaikan ratarata sampai dengan 15 hari, dimana hampir $3 \mathrm{x}$ lipat dari target. Selanjut nya dari sisi inovasi produk dan proses internal menunjukan score 
yang jelek, dimana hasilnya adalah kurangnya penambahan produk baru yang sangat minim, tidak adanya penambahan supplier baru membuat bargaining power dari existing supplier menjadi cukup tinggi. Faktor lainnya adanya larangan dari supplier untuk menjual brand tertentu. Pada segi bisnis internal pun sama, tidak ada perubahan SOP sejak 2017 sampai sekarang. Walau sudah terjadi turnover karyawan, sistem masih tetap yang lama dan belum terbaharui.

\section{Pengukuran Kinerja Perspektif Learning and Growth}

Tabel 8 BSC Perspekif Learning \& Growth

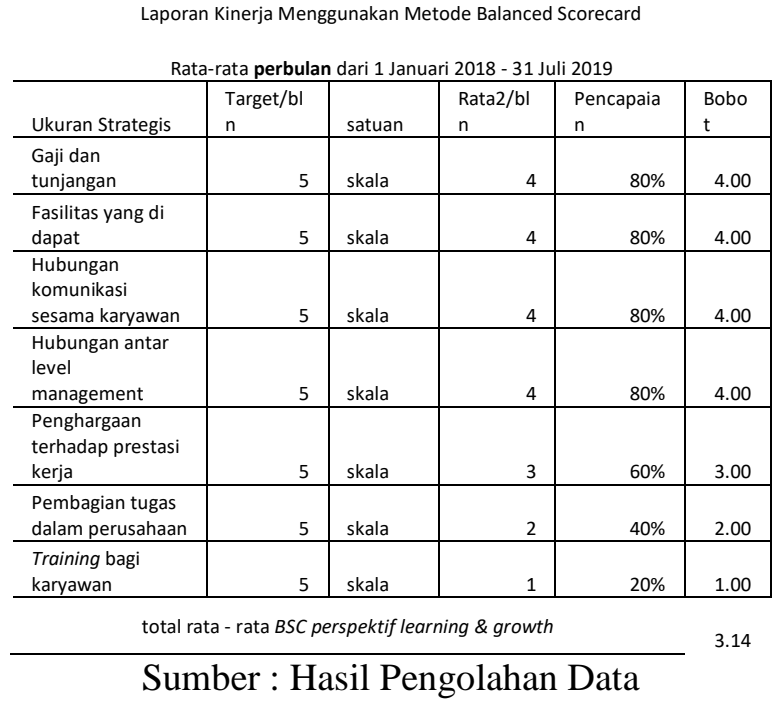

Tabel 8 adalah BSC dalam perspektif Learning and Growth, dalam perspektif ini, menurut data yang didapat karyawan senang bekerja di PT APG, namun yang lemahnya di perspektif ini adalah di bagian penghargaan prestasi kerja yang dimana karyawan berharap adanya rewarding yang lebih, terlebih lagi tidak ada bonus yang besar selain pada THR lebaran. Dan yang selanjutnya lagi yang perlu di cermati adalah di training bagi karyawan, hasil data pun menunjukkan tidak ada yang perduli dengan training, namun penulis beri 1 karena tidak adanya pelatihan khusus.
Pelatihan hanyalah dari yang senior ke yang junior, tidak ada standard yang pas.

Hasil score keseluruhan dari BSC PT. AGP, dapat dilihat pada gambar 4

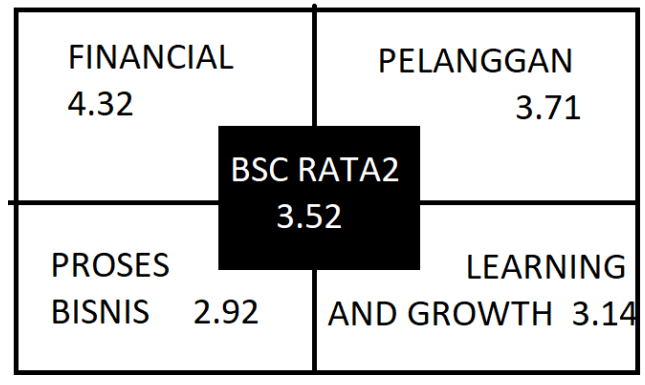

Gambar 4 Hasil Pengukuran BSC PT AGP (Sumber : Hasil Pengolahan Data)

\section{Saran Untuk Langkah Kedepannya}

Prioritas perbaikan yang prioritas pada perspektif proses bisnis yang nilainya masih dalam skala buruk. Training berkala untuk karyawan penting setidaknya itikad dari direktur untuk menargetkan rata-rata training ada lima kali dalam satu bulan sudah sangat baik, lima kali dalam satu bulan maksudnya adalah berbagai divisi, misalnya minggu pertama divisi penjualan lalu pemasaran, lalu minggu kedua adalah bagian accounting, minggu ketiga bagian operasional, dan minggu ke empat adalah bagian warehouse. Training bukan hanya untuk mengajari hal baru, tapi juga berguna untuk recall kegiatan yang jarang dilakukan dan tetap dapat terlaksana semua dengan prosedur.

Selanjutnya dari perspektif customer menunjukan referral dari existing sangat lah sedikit, sehingga perusahaan perlu untuk mulai berusaha menambahkan customer baru dengan aktif, agar market perusahaan tidak terus tergerus, tapi juga ada yang baru.

Perusahaan perlu untuk menambahkan lini product, setidaknya menambah supplier baru, karena di perspektif ini sangat rendah dan membuat bargaining power dari supplier tinggi. Malah jika memungkinkan mulai untuk memulai brand sendiri.

Melakukan re-assigning job description karena beberapa system sudah tidak sesuai dengan karyawan yang baru, 
harus di sesuaikan lagi dan perlu mengisi kursi- kursi yang memang kosong supaya tidak terlalu pembebanan di individu- individu tertentu.

Terutama untuk aftersales service harus ditingkatkan, karena banyak complain dari customer itu bukan dari produknya tapi dari pelayanan aftersales yang lambat.

\section{SIMPULAN}

Berdasarkan hasil penelitian yang telah dilakukan dan pembahasan pengukuran kinerja dengan metode Balanced Scorecard terhadap PT AGP maka dapat disimpulkan secara keseluruhan score PT AGP masih termasuk sehat dimana mendapatkan rata-rata 3.52 dari 5. Balanced Scorecard membuat perspektif yang lebih luas tidak hanya finansial, namun juga perspektif pelanggan, proses bisnis, dan pembelajaran dan pertumbuhan. Dapat ditarik beberapa kesimpulan antara lain sebagai berikut Pertama, penurunan penjualan yang terjadi, tidak semata-mata hanya karena faktor finansial, namun dengan Balanced Scorecard, aspek lain dari keuangan ikut terdeteksi, dimana ada beberapa kelemahan di aspek pendukung lainnya. Yang paling terlihat adalah aftersales yang lambat yang membuat pelanggan komplain. Kedua, disimpulkan dari hasil penelitian, kepuasan karyawan tinggi, dimana karyawan senang dan puas untuk bekerja di PT AGP, namun system rewarding tetap harus diperbaiki agar karyawan tidak berpikir overworking, dan mendapatkan sesuai dengan kinerjanya. Pelatihan dan pengembangan diri sebaiknya di mulai, bisa dengan FGD dan sharing knowledge. Ketiga, PT AGP sebaiknya menambah variatif pemasoknya, untuk meningkatkan bargaining power, dan variasi produk. Penambahan kategori produk juga menjadi masukan bagi PT AGP. Keempat, perlu penelitian selanjutnya untuk breakdown kelemahan pada proses bisnis dan memperbaikinya dan memberikan SOP yang cocok.

\section{DAFTAR PUSTAKA}

Andry, J. F (2018), Conceptual Framework for Successful IT-Governance and BSC for Service Industry, International Journal of Innovative Science and Research Technology, ISSN No:-2456-2165, Jakarta

Erwin, Prabowo, H. (2015). Analisis Pengukuran Kinerja Menggunakan Metode Balanced Scorecard Pada PT. Bahtera Utama. Binus Business Review

Hardiyanto, Y., Ali, A. H. N., Pambudi, H. A. (2005). Perancangan dan Pembuatan Sistem Informasi Pengukuran Kinerja Pemasaran dengan Metode Balanced Scorecard studi Kasus PT. Semen Gresik. Surabaya: Institut Teknologi Sepuluh November

Kaplan, RS, and DP Norton, 1996b, 'Using the Balanced Scorecard as a strategic management system', Harvard Business Review, 74 (1): 75-85.

Liputan6.com (2019). Sri Mulyani: Pertumbuhan Ekonomi Indonesia 2019 Hanya 5,08 Persen, diakses pada tanggal 10 September 2019. Dari : https://www.liputan6.com/bisnis/read/ 4050253/sri-mulyani-pertumbuhanekonomi-indonesia-2019-hanya-508persen

Luis, S., Biromo, P. A. (2010). Step by Step in Cascading Balanced Scorecard to Functional Scorecard. Jakarta: PT Gramedia Pustaka Utama.

Menkop. Perkembangan Data Usaha Mikro, Kecil, dan Menengah (UMKM) dan Usaha Besar (UB) Tahun 2010-2015, diakses pada tanggal 3 September 2019 dari http://www.depkop.go.id/data-umkm 
Sarjono, H., Pujadi, A., Wong, H. W. (2010).

Penerapan Metode Balanced

Scorecard Sebagai Suatu Sistem

Pengukuran Kinerja pada PT.Dritama

Brokerindo. Binus Business

Review,1(1): 139154.

Sugiyono, P. D. (2017). Metode Penelitian

Bisnis: Pendekatan Kuantitatif,

Kualitatif, Kombinasi, dan R\&D.

Penerbit CV. Alfabeta: Bandung.

World Bank (2019). Laju Pertumbuhan Ekonomi Global, diakses pada tanggal

3 September 2019 dari

https://ekonomi.kompas.com/read/201

9/01/09/101500026/bank-dunia--lajupertumbuhan-ekonomi-global-2019-

melemah 